\title{
Utilization of lodized Salt and Associated Factors Among Pregnant Mothers in Kimbibit District, North Shoa Zone, Oromia Regional State, Ethiopia
}

\author{
Tola Abera ${ }^{1,}$, , Haji Aman Deybasso², Ebrahim Mohammed Gebaba ${ }^{2}$ \\ ${ }^{1}$ Barak Woreda Health Office, Sendafa Beke, Ethiopia \\ ${ }^{2}$ Department of the Public Health, Adama Hospital Medical College, Adama, Ethiopia \\ Email address: \\ tola12abera@gmail.com (T. Abera), hajia.aman9@gmail.com (H. A. Deybasso), Ebrahim.M805@gmail.com (E. M. Gebaba) \\ ${ }^{*}$ Corresponding author
}

\section{To cite this article:}

Tola Abera, Haji Aman Deybasso, Ebrahim Mohammed Gebaba. Utilization of Iodized Salt and Associated Factors Among Pregnant Mothers in Kimbibit District, North Shoa Zone, Oromia Regional State, Ethiopia. American Journal of Health Research.

Vol. 9, No. 3, 2021, pp. 89-99. doi: 10.11648/j.ajhr.20210903.14

Received: May 3, 2021; Accepted: June 7, 2021; Published: June 21, 2021

\begin{abstract}
Globally, it has been reported that $38 \%$ of people live in areas with iodine deficiency and are at risk of its complications. The main health concern of iodine deficiency during pregnancy is its negative effect on the brain and nervous system of unborn infants. Despite the national availability of iodized salt was $89 \%$, adequate utilization of iodized salt is only $41.9 \%$. Hence, this study was to assess utilization of iodized salt and factors associated among pregnant mothers in Kimbibit District. Community based cross-sectional study design was conducted. Simple random sampling technique was used to select a total sample of 555 pregnant mothers. Single population proportion formula and Stat. calc software were used to calculate the required sample size. Data were collected using interview administered pretested questionnaire and iodized salt test kit. Collected data were entered using Epi info 7 and then exported to SPSS 20 for further analyses. Descriptive statistics were used to describe important variables and binary logistic regression was used to identify candidate independent variables. $\mathrm{P}<$ 0.05 was used for testing significance and AOR with $95 \% \mathrm{CI}$ was used to identify the strength of association between dependent and independent variables. From the total respondents, 48.1\% (95\%CI: 44.1\%, 52.1\%) of them adequately use iodized salt. Mother with formal education (AOR, 2.46; 95\%CI: 1.70, 3.56), urban residents (AOR, 1.80; 95\%CI: 1.14, 2.93), purchasing from open markets (AOR, $0.35 ; 95 \% \mathrm{CI}: 0.23,0.50$ ), storing at sun light (AOR, $0.24 ; 95 \% \mathrm{CI}: 0.13,0.45)$ and storing more than two months (AOR, 0.64; $95 \% \mathrm{CI}: 0.42,0.98)$ were independent factors significantly affect adequate utilization of iodized salt. Utilization of iodized salt was low compared to the standard. Mother's education, residence, place of purchase, place of storage and duration of storage were independent factors which significantly affect adequate utilization.
\end{abstract}

Keywords: Iodized Salt, Pregnant Mothers, Kimbibit, Adequate Utilization

\section{Introduction}

Iodine plays a vital role in the synthesis of thyroid hormone which is responsible for the regulation of basal metabolic rate, growth, development and functioning of the central nervous system (CNS) which effects on different organs and organ systems. It is essential in the development of the CNS during embryonic and fetal life $[1,2]$. The magnitude of the deficiencies of iodine is widely varied among different target groups, hence targeted intervention required to address the deficiency [3]. Due to increased metabolic demand, pregnant mother's (PM's) requirements are increased by more than half for adequate iodized salt (IS) [4-6]. This suggests that iodine is an essential micronutrient during pregnancy. Pregnancy is associated with parallel increase in thyroid hormone requirements due to physiological modifications emanating from the transfer of iodine and the thyroid hormone to the fetus for proper neurodevelopment in children $[7,8]$.

Iodine is gained through utilization of foods that naturally contain it such as fish, drinking water, Cow's milk and vegetables grown in sufficiently iodine containing soil or IS 
[9]. Iodine deficiency (ID) is mainly caused by low iodine content in the diet, arising from low iodine levels in the soil [10], water, or crops. In addition, the consumption of goitrogenic substance containing food like cassava and millet, poor household $(\mathrm{HH})$ socio-economic status, low maternal education, advanced age and sex of the child are some of the factors associated with ID [11].

Iodized salt is both a preventive and corrective measure for ID and is the most effective, low cost and long-term solution to iodine deficiency disorders (IDDs) $[12,13]$. In Australia and New Zealand Food fortification is used to reduce IDDs. They use IS in bread-making and exclude bread marked as 'organic' from complying with these requirements in both countries. Food Standards in countries marked the beginning of mandatory iodine fortification of food [8].

Iodized salt is the main source of dietary iodine to control the IDDs [14]. Hence, universal salt iodization (USI) is recommended as the most cost-effective, safe and sustainable strategy to eliminate IDDs. According to World Health Organization (WHO)/United Nations Children's Fund (UNICEF) in order to achieve sustainable elimination of ID, at least $90 \%$ of $\mathrm{HHs}$ must use salt that contain $\geq 15 \mathrm{ppm}$ iodine $[15,16]$. For the loss during transportation, $\mathrm{WHO} / \mathrm{UNICEF}$ recommends that the salt iodine content at the packaging level must be $50-60 \mathrm{ppm}$ and $20-30 \mathrm{ppm}$ at the retail level to achieve at least $15 \mathrm{ppm}$ in the $\mathrm{HH}$ dietary consumption [17, 18]. Adequate iodine nutrition among PM is ensured when the salt iodine content rose to $30 \mathrm{ppm}$ at the $\mathrm{HH}$ level [19]. In Ethiopia, utilization of adequately IS shows a gradual improvement, $4 \%$ in 2000 to $15 \%$ in 2011 and $23 \%$ in 2014. According to Ethiopian demographic and health survey (EDHS), in 2015, the national coverage is $89 \%$. However, only about $26 \%$ of the surveyed HHs had salt that is adequately iodized [20].

Iodine deficiency remains a considerable challenge worldwide, even after decades of efforts to address the problem. It is still a challenge for both developed and lessdeveloped countries. For example, seven of the top 10 affected countries are in Africa and Europe where 44\% are with inadequate iodine supply worldwide [21].

Iodine deficiency is more severe in high land areas and in densely populated plains [22]. In mountainous, the top layer of the soil is eroded and leading to leaching away of iodine which causes crop cultivation is close to iodine free [23]. As a result, ID is recognized as a major public health problem, and the threat it poses to the health and development of the population still appears large. Study revealed a Total Goiter Prevalence (TGP) of $30.1 \%$ and $54 \%$ in mothers and their children respectively. Younger age mother are more affected than older and female are more affected than male ones [24].

About $38 \%$ of the world's population live in areas with ID and are at risk of its complications [2]. At least 350 million Africans are at risk of ID [25]. According to WHO estimates, goiter presents in $28.3 \%$ of the African population and approximately $25 \%$ of the global burden of ID as measured by disability-adjusted life years occurs in Africa [28]. Almost $40 \%$ of children under five years of age in low- and middle income countries do not reach their full developmental potential, and ID is among the main risk factors [27].

Globally, $30 \%$ of the world's population is affected by IDD and more than 150,000 million people are affected in Africa alone [10]. The TGP in the general population is estimated to be $15.8 \%$, varying between $4.7 \%$ in America to $28.3 \%$ in Africa and the GPR is higher in females than males in different studies in the world [28]. About 33\% of HHs in the developing world does not get enough iodine, and a result is often impairment in brain formation in the fetal stages. Furthermore, the adverse health consequences of ID can lead to reductions in both productivity and intellectual potential in adulthood [17]. Lower school performance and absenteeism are significantly higher among students with goiter [29]. This particularly affects female fetuses and typically costs children 10 to 15 IQ points, hence $1.48 \%$ extra social expenditure for education [30-32]. Addition of iodine to salt beginning in 1924 increased IQ in America by 15 points [33].

Globally, more than 1.88 billion people have inadequate iodine intake [21]. A diet which lacks iodine is associated with a wide spectrum of adverse health effects collectively known as IDDs (1). IDDs have a number of medical consequences: decreased physical growth, mental retardation; decreased fertility, increased prenatal death; cretinism and infant mortality. Inadequate intakes of iodine can contribute to birth defects and the inability of the child to develop his or her full cognitive potential [34]. Although globally iodine nutrition has greatly improved, $20 \%$ to $30 \%$ of pregnancies and newborns still do not fully benefit from the use of IS [25]

More than 50\% mothers have insufficient iodine level with mothers leaving in rural had insufficient intake of iodine than those from urban [3]. Iodine deficiency in PMs result in serious damage to their fetuses, newborns, and infants. Abortion \& still birth are one of the most dreadful outcomes with inadequate iodine intake during pregnancy $[5,35]$.

The survived infants born from such mothers may also have severe mental problems such as congenital anomalies, speech and hearing impairment and cretinism, which essentially is the severe form of mental retardation, and is by far the most serious health consequences of ID in PMs [12, 28]. In addition to its health consequences, ID has negative social impacts. A deformed physical appearance entails psychological tensions, and is considered to reduce chances for marriage [15].

In Ethiopia, as of IDDs 1 per 1000 is a cretin, about 50,000 perinatal deaths are occurring annually due to IDDs, Some pocket areas of the country have TGR of 50 - 95\% [29] and it is estimated that 100,000 children born each year are at risk of IQ impairment because of ID, which results in an average of 22 million dollars loss in productivity each year [10, 36].

The Ethiopian government has shown tireless commitment to combat ID through mandatory USI and health sector transformation plan (to address $80 \%$ HHs with iodized salt) in 2011 and 2015, respectively. In 2016, the government launched the second national nutrition program (NNP) cycle focusing on the first 1,000 days of life to Control of micronutrient deficiencies in the most vulnerable populations 
among which PM is one of the program's key targets by 2030 [19].

There is a desirable variation among in utilization practices in using IS at $\mathrm{HH}$ level [37]. Issues about awareness in utilization of IS, loss of the iodine from the IS due to poor handling, cooking methods and storage at $\mathrm{HH}$ level remain a big challenge [38].

Regional studies of ID in Ethiopia are incomplete [23]. Studies on practice of IS utilization are insufficient (10). In Oromia, the largest populated region, most zones and districts have no information, including North Shoa zone [23].

Therefore, this study assessed the utilization of IS and associated factors among PM at $\mathrm{HH}$ level. It also tried to solve the problem of $\mathrm{HH}$ utilization of iodized salts by identifying the major factors associated. This study is also important to measure iodine adequacy in salts and documentation of losses at the consumer's level compared to the national coverage. It is also important to monitor what percentage of the population remains at risk of insufficient intake of iodine. In the study area, people were practicing inadequate utilization of iodized salt at $\mathrm{HH}$ level and factors associated were not yet assessed. The findings of this study will help the local government to know the problem and give insight to the concerned parties to work more effective on it. The findings are expected to be useful to district administration, district health office and other concerned stakeholders to share responsibility, know the factors associated with it and take measures on the factors identified. In addition to this the findings and subsequent recommendations may be helpful for scientific communities.

\section{Methods and Materials}

\subsection{Study Area and Period}

Kimbibit District is found in North Shoa of Oromia regional state, 76 kilometer $(\mathrm{km})$ from Addis Ababa (capital of the nation) to the North, at a geographic location of $9.33^{\circ}$ latitude and $39.3^{\circ}$ longitude at an elevation of 2918 meters above sea level. It has an estimated area of $861.3 \mathrm{~km}^{2}$. The district has 2 urban and 29 rural kebeles. The total population of Kimbibit in 2020 as projected based on the 2007 census data is 104,924 residents $(19.89 \%$ urban and $80.11 \%$ are rural $)$ made up of $21,860 \mathrm{HHs}$. The climate condition of the district is totally "Dega". The district has 4 health centers, 29 health posts, one ongoing district hospital, 4 private clinics and 4 private pharmacies. The number of pregnant mothers is estimated to be 3641 . The main sources of employment and income for its residents, according to information obtained from the district administration, is agriculture, government employment and commercial activity related to agriculture. Trade in agricultural products mainly dairy butter and various pulses and cereals grains are dominant. The study was conducted from July 1-30, 2020 for thirty consecutive days.

\subsection{Study Design}

A community based cross-sectional study was conducted.

\subsection{Source and Study Populations}

\subsubsection{Source Population}

All pregnant mothers in Kimbibit district were source population.

\subsubsection{Study Population}

All pregnant mothers who were in randomly selected kebeles during the study period were study population.

\subsection{Study Units}

Individual pregnant mothers randomly selected were study units

\subsection{Eligibility Criteria}

\subsubsection{Inclusion Criteria}

All pregnant mothers who lived in the district for six months or more were included [17].

\subsubsection{Exclusion Criteria}

Pregnant mothers who were seriously ill and those with salt restriction (Chronic hypertension) were excluded.

\subsection{Sample size and Sampling Procedure}

\subsubsection{Sample Size Determination}

The sample size for the study was calculated using single population proportion formula considering adequate utilization of IS $41.9 \%$ in Oromia region (34), 95\% confidence level, $4 \%$ margin of error and $10 \%$ were added for the expected no response. The final sample size was $\mathbf{5 5 5}$ pregnant mothers. The formula to determine the sample size was below:-

$$
\begin{gathered}
\mathrm{n}=\frac{(\mathrm{Z} \alpha / 2)^{2} \times \mathrm{P} \times(1-\mathrm{P})}{\mathrm{d}^{2}} \\
\mathrm{n}=\frac{(1.96)^{2} \times(0.419) \times(0.581)}{0.04^{2}}=585
\end{gathered}
$$

Where, in the study:

1) $\mathrm{P}=$ Percentage of mothers who were used the iodized salt $(41.9 \%)$

2) $1-p=$ Percentage of mothers who were not used the iodized salt (58.1\%)

3) $n=$ study participants (740)

Margin of error

$(d)=Z \alpha / 2 \sqrt{\frac{p(1-p)}{n}} d=1.96 * \sqrt{\frac{0.419 *(1-0.419)}{740}}=0.04$

1) Level of significance Standard normal value at $95 \% \mathrm{CI}=1.96$

2) Then, the total sample size, $\mathrm{n}_{0}$ is 585 .

3) As the source population is less than 10,000 (that is 3641 , we need to apply correction formula) 


$$
\mathrm{n}=\frac{\mathrm{n}_{0}}{\left(1+\frac{\mathrm{n}_{0}}{\mathrm{~N}}\right)}
$$

Where

$\mathrm{n}=$ required sample size when source population were $<$ 10,000

$\mathrm{N}=$ Population (3641)

Therefore, $\mathrm{n}=585$

$$
1+\frac{585}{3641}=504
$$

1) For possible no response during the survey the final sample size was increase by $10 \%$. That is, $\mathrm{n}=504+504 * 10 \%$ which is $504+51=555$.

2) Sample size was calculated for some of the associated factors obtained from different literatures using the Statcalc of Epi Info statistical software version 7 with the same assumptions above.

The sample size for associated factors were smaller than 555 of the dependent variable. Hence 555 were selected as sample size for the study.

Table 1. Major associated factors and their calculated sample sizes.

\begin{tabular}{llllll}
\hline Associated factors & Power & CI & Proportion & AOR & Calculated sample size \\
\hline Information level & 80 & 95 & 35.8 & 2.11 & 527 \\
Residence & 80 & 95 & 21.4 & 2.15 & 311 \\
Socioeconomic & 80 & 95 & 18.6 & 1.99 & 365 \\
\hline
\end{tabular}

\subsubsection{Sampling Procedure}

The district was stratified based on their residence, 2 urban and 29 rural kebeles (the lowest administrative unit in Ethiopia). In the first stage, kebeles were selected to determine representative sample for the district and get adequate sample. Since the 2 urban kebeles are homogenous in terms of iodized salt utilization, 1 kebele was selected using simple random sampling. Similarly since 29 rural kebeles were homogenous, 3 kebeles were chosen using simple random sampling and a total of 4 kebeles were selected from the district. Then, sample size was distributed across the selected kebeles with probability proportional to the size of the estimated number of PMs in each kebele. Pregnant mothers live in the selected kebeles were identified through house to house visits by HEWs and taken as sampling frame. Using a simple random sampling technique, pregnant mothers were selected and interviewed. For pregnant mothers who are not found at home, the interviewers revisited the $\mathrm{HH}$ two times at different time intervals and when interviewers failed to get them, the respondent were registered as non-response.

\subsection{Variables}

\subsubsection{Dependent Variable}

Utilization of iodized salt

\subsubsection{Independent Variables}

Socio-demographic and socio-economic factors (education, residence, occupation, income, family size, marital status, age), practice (storage site, time to add salt), availability/accessibility, awareness level and taste were independent variables.

\subsection{Operational Definition}

1) Adequate utilization of iodized salt: Having iodized salts, adding to cooking at the end or right after cooking in the last 24 hour, otherwise considered as inadequate utilization [37].
2) Adequately iodized salt: Pregnant women who use salts with $\geq 15 \mathrm{ppm}$ iodine when it was tested with RTK in their home have adequately iodized salts; otherwise it was taken as inadequately iodized [39].

3) Storage of iodized salt: mothers who store the purchased iodized salt for more than two months were considered as having longer storage time, and those who stored for less than two months considered were taken as having shorter storage time [40].

\subsection{Data Collection Procedure}

Data collectors introduced briefly the information to the respondent. After consent obtained from participants, questionnaire was completed by face to face interview in Afaan Oromo and the salt was tested for its iodine content. Quality of iodine test kit was assured by observing its expiry dates and its proper use was assured through training of data collectors and supervisors. Data were collected from targeted PMs, with HEWs of that kebele as guider, every day starting from 4:00 AM local time. One extra visit was made to absentees HHs, before substitution to the next Sample HH. To assess practices and minimize recall bias data collectors used 24 hours recall period.

\subsection{Measurement Procedures}

For the determination of availability of adequately IS, the interviewer asked every sample $\mathrm{HH}$ to provide a teaspoon of salt used for food preparation and fill small cup spread flat, added two drop of test solution on surface of salt by piercing the white ampule and compare color on salt with color chart with one minute and determine the iodine concentration (intense color). If no color change appeared on the salt (after one minute), on a fresh sample added up to 5 drop of recheck solution in red ampule and the 2 drops of test solution on same spot and compared the color with color chart and determine iodine content. The cut-off $<15 \mathrm{ppm}$ (Light blue) and $\geq 15 \mathrm{ppm}$ (Deep blue) color was used. This was determined by using improved IS Field test kit B. NO 011, 
MFG JAN 2018, EXP NOV 2020 for salt fortified with potassium iodate only. Unopened ampules were used and, the kit is accurate for visual detection of potassium iodate concentration at threshold of $15 \mathrm{ppm}$ and result is valid. The test kits were obtained from UNICEF through Oromia Regional Health Bureau.

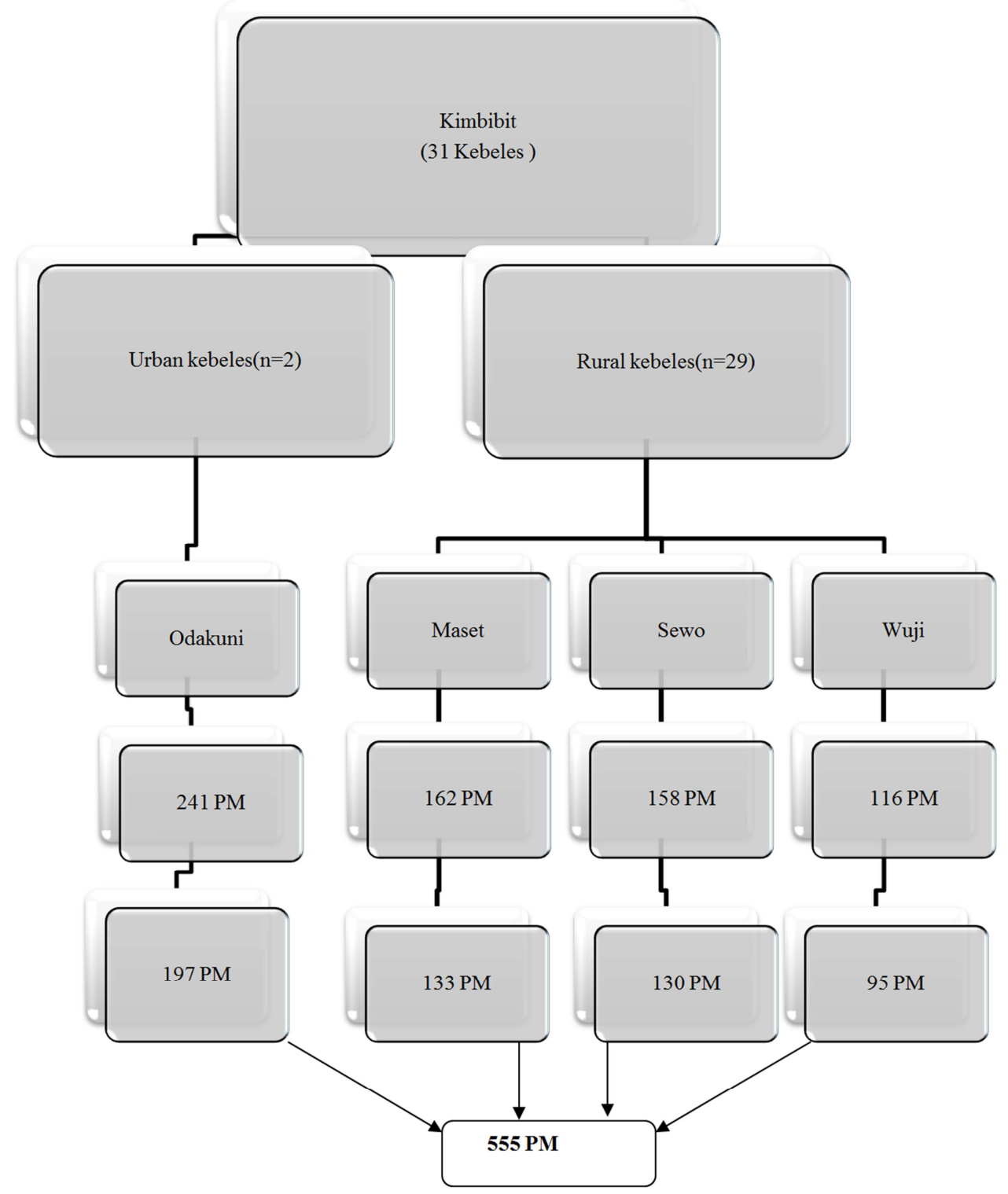

Figure 1. Sampling procedure of iodized salt utilization among pregnant mothers and associated factors in Kimbibit District, Oromia, Ethiopia in 2020.

\subsection{Data Quality Assurance}

Eight clinical nurses as data collectors and two BSc nurses as supervisors who knew Afaan Oromo and familiar with local culture were recruited. This helped pregnant mothers to communicate easily with data collectors which were useful to generate important information. The questionnaire were developed in English and then translated to Afaan Oromo and finally retranslated to English to check its consistency. One day training was given for the data collectors and supervisors on how to complete the questionnaire and test salt sample. Before actual data collection, questions were piloted and pre-tested, five days prior to actual data collection, for completeness, consistency, and timeliness on 5\% residents of Aleltu district having similar socio-demographic background, who were not part of the study. After piloted and pre-tested, the necessary modifications were made in the questionnaire. Supervisors were checked filled questionnaire and contacted at least 3\% of the respondents to verify that the correct procedures has been followed in data collection and testing for IS. Regular meetings were held every other day between the data collectors, supervisors and the principal investigator to discuss problematic issues arising from interviews conducted. Daily feedback was given by the investigator and supervisors during the entire data collection period to maintain the quality of the data. Incomplete questionnaires were taken back immediately to the respondents for completion.

\subsection{Data Processing and Analysis}

After completion of data collection from sample mothers, 
each questionnaire were checked and screened for completeness and consistency. Omissions, errors, completeness, were checked by principal investigator. Data were cleaned, edited, and coded before entry. Data entry were made by Epi info version 7 software and transferred to SPSS version 20 for analysis. Before Analysis data were prepared using transform menu. Computing, count, recoding were performed. Adequately IS at $\mathrm{HH}$ level were defined as salt $\geq$ $15 \mathrm{ppm}$ of iodine and if salt sample has $<15 \mathrm{ppm}$ of iodine, it was defined as inadequately iodized salt. Data processing was done before analysis. Descriptive statistics was used to summarize the study results and examined for distribution of dependent and independent variables. Frequency distribution, central tendency, and desperation are used to describe the shape of variable distribution and for subsequent analysis. Variables having $P$ value $\leq 0.25$ in the simple logistic regression analysis were entered into multiple logistic regression models for control of confounding. Multiple logistic regression models were built with backward logistic regression method.

The Model fitness for Logistic regression were tested ( $p$ value 0.341) using Hosmer-Lemeshow goodness of fit test at $\mathrm{P}$-Value $>0.05$. The strength of the association was described by adjusted odds ratio (AOR) with Confidence interval (CI) of $95 \%$ and $\mathrm{P}$-Value $<0.05$ was considered as a significant result in multiple logistic regression analysis. Controlling of known and potential confounding factors with adequate utilization of IS at $\mathrm{HH}$ level were assessed by multiple logistic analysis.

\subsection{Ethical Considerations}

The proposal was ethically reviewed and approved by the institutional review board of Adama hospital medical College. The letter of support was obtained from College of Public Health and permission was obtained from Kimbibit district administration and Health Office.

Kebele administrators and interviewers were informed about the purpose of study, importance and duration of the study in order to get their free time and prior informed consent for the survey. Confidentiality was maintained and respondents were informed that participation is voluntary and they can withdraw at any time from the study. The right of participants to anonymity and confidentiality were ensured by making the questionnaire anonymous.

Verbal informed consent was obtained from all mothers who were involved in the study before the interview and the information given were kept confidential throughout the data collection.

\section{Results}

\subsection{Socio-demographic and Economic Characteristics}

A total of 555 pregnant mothers were included in the study with a response rate of 100\%. About $217(39.1 \%)$ of mothers are within the age of 26-35 years category. Majority (68.5\%) of the respondents are Orthodox by religion, $441(79.5 \%)$ lives in rural, 427 (76.9\%) were married, $104(18.7 \%)$ of them had more than 5 Five family members, 184 (33.2\%) had a monthly income of $<1500$ Birr, 227 (40.9\%) are housewife by occupation and $290(52.3 \%)$ do not attend formal education [Table 2].

Table 2. Socio-demographic and economic characteristics of the respondent in Kimbibit district, Oromia, Ethiopia, 2020 (n=555).

\begin{tabular}{|c|c|c|}
\hline Variables & Frequency (n) & Percent (\%) \\
\hline \multicolumn{3}{|l|}{ Religion } \\
\hline Orthodox & 380 & 68.5 \\
\hline Muslim & 85 & 15.3 \\
\hline Protestant & 83 & 15.0 \\
\hline Others & 7 & 1.3 \\
\hline \multicolumn{3}{|l|}{ Marital status } \\
\hline Single & 70 & 12.6 \\
\hline Divorced & 42 & 7.6 \\
\hline Widowed & 16 & 2.9 \\
\hline \multicolumn{3}{|l|}{ Family size } \\
\hline$<=5$ & 451 & 81.3 \\
\hline$>5$ & 104 & 18.7 \\
\hline \multicolumn{3}{|l|}{ Mother's education } \\
\hline No education/illiterate & 290 & 52.3 \\
\hline Secondary school & 48 & 8.6 \\
\hline College diploma and above & 92 & 16.6 \\
\hline \multicolumn{3}{|l|}{ Residence } \\
\hline Rural & 441 & 79.5 \\
\hline Urban & 114 & 20.5 \\
\hline \multicolumn{3}{|l|}{ Occupation of mothers } \\
\hline Housewife & 227 & 40.9 \\
\hline Private business & 215 & 38.7 \\
\hline Employee & 110 & 19.8 \\
\hline Others & 3 & 0.5 \\
\hline \multicolumn{3}{|l|}{ Mother's monthly income } \\
\hline$<1500$ & 184 & 33.2 \\
\hline
\end{tabular}




\begin{tabular}{lll}
\hline Variables & Frequency (n) & Percent (\%) \\
\hline $1501-2800$ & 163 & 29.4 \\
$2801-5000$ & 189 & 34.1 \\
$>5000$ & 19 & 3.4 \\
Age of mothers (in years) & & \\
$15-25$ & 197 & 35.5 \\
$26-35$ & 217 & 39.1 \\
$>35$ & 141 & 25.4 \\
\hline
\end{tabular}

\subsection{Iodized Salt Utilization Among Pregnant Mothers}

\subsubsection{Information and Level of Awareness}

About $234(42.2 \%)$ and $213(38.4 \%)$ of the respondents had no any information on iodized salt and IDD respectively. Less than a quarter of them, $134(24.1 \%)$, got information from health professionals. Three hundred sixteen $(56.9 \%)$ of the respondents knew goiter as IDDs. All of the mothers, 555 $(100 \%)$ had salt but only $301(54.2 \%)$ of them knew that their salt was iodized before the test result. Two hundred and twelve $(38.2 \%)$ of had information about the advantage of iodized salt [Table 3].

Table 3. Information and level of awareness about iodized salt among pregnant mothers in Kimbibit district, Oromia, Ethiopia, 2020 ( $n=555)$.

\begin{tabular}{|c|c|c|}
\hline Variables & Frequency (n) & Percent (\%) \\
\hline \multicolumn{3}{|l|}{ Have you heard about iodized salt? } \\
\hline No & 234 & 42.2 \\
\hline Yes & 321 & 57.8 \\
\hline \multicolumn{3}{|l|}{ Do you heard about IDDS on human health? } \\
\hline No & 213 & 38.4 \\
\hline Yes & 342 & 61.6 \\
\hline \multicolumn{3}{|l|}{ If yes, source of information? } \\
\hline Health professionals & 134 & 24.1 \\
\hline Neighbors & 85 & 15.3 \\
\hline Radio/Television & 117 & 21.1 \\
\hline Literatures & 76 & 13.7 \\
\hline Others (teachers, relatives) & 8 & 1.4 \\
\hline \multicolumn{3}{|l|}{ Do you think all salts have iodine? } \\
\hline No & 193 & 34.8 \\
\hline Yes & 187 & 33.7 \\
\hline I don't know & 175 & 31.5 \\
\hline \multicolumn{3}{|c|}{ Is using iodized salt important for human health? } \\
\hline No & 43 & 7.7 \\
\hline Yes & 356 & 64.1 \\
\hline I don't know & 156 & 28.1 \\
\hline \multicolumn{3}{|l|}{ Which IDDS do you know? } \\
\hline Goiter & 316 & 56.9 \\
\hline Mental health & 69 & 12.4 \\
\hline Abortion & 58 & 10.5 \\
\hline Still birth & 33 & 5.9 \\
\hline $\begin{array}{l}\text { Others (IQ loss, physical deformity, } \\
\text { death) }\end{array}$ & 129 & 23.2 \\
\hline \multicolumn{3}{|l|}{ How can we prevent IDDS? } \\
\hline Play sports & 79 & 14.2 \\
\hline Use iodized salt & 297 & 53.5 \\
\hline Making tattoo & 54 & 9.7 \\
\hline $\begin{array}{l}\text { Others (eat iodine containing foods, do } \\
\text { not know) }\end{array}$ & 146 & 26.3 \\
\hline \multicolumn{3}{|l|}{ Advantage of iodized salt over non-iodized } \\
\hline Better taste & 106 & 19.1 \\
\hline Easily soluble & 134 & 24.1 \\
\hline Replace iodine deficiency & 212 & 38.2 \\
\hline Others (prevent goiter, easily soluble, taste) & 139 & 25.0 \\
\hline
\end{tabular}

\subsubsection{Practices Related to Iodized Salt Utilization}

With respect to practices majority $(61.6 \%)$ of mothers use the unpacked salt, Two hundred and eighty four (51.2\%) of them bought their salt from markets and about 165 (29.7\%) of them travelled a distance of more than 60 minutes walking Most mothers (91.2\%) store their salt in covered container. About 304 (54.8\%) mothers use local salts with a quarter of mothers $(25.4 \%)$ store their salt for more than two months while about $295(53.2 \%)$ use it as was bought. With respect to storage site, about $329(59.3 \%)$ keep their salt as recommended in dry area. Adequately iodized salt is found in $326(58.7 \%)$ salt samples [Table 4].

Table 4. Iodized salt utilization practices among pregnant mothers in Kimbibit district, Oromia, Ethiopia, 2020 ( $n=555)$.

\begin{tabular}{|c|c|c|}
\hline Variables & Frequency (n) & Percent (\%) \\
\hline \multicolumn{3}{|l|}{ Which salt do you use? } \\
\hline Packed & 213 & 38.4 \\
\hline Unpacked & 342 & 61.6 \\
\hline \multicolumn{3}{|c|}{ Why do you use unpacked salt? } \\
\hline Cheap & 176 & 31.7 \\
\hline Easily available & 47 & 8.5 \\
\hline Stays long & 107 & 19.3 \\
\hline Others (custom, taste) & 10 & 1.8 \\
\hline \multicolumn{3}{|c|}{ From where do you buy your salt? } \\
\hline Shops & 212 & 38.2 \\
\hline Markets & 284 & 51.2 \\
\hline Others (bazars, wholesale) & 59 & 10.6 \\
\hline \multicolumn{3}{|c|}{ Do you store your salt in covered container? } \\
\hline No & 49 & 8.8 \\
\hline Yes & 506 & 91.2 \\
\hline \multicolumn{3}{|c|}{ For how long do you store your salt? } \\
\hline$<=2$ months & 414 & 74.6 \\
\hline$>2$ months & 141 & 25.4 \\
\hline \multicolumn{3}{|l|}{ How do you use your salt? } \\
\hline As was bought & 295 & 53.2 \\
\hline Wash when gets darken & 96 & 17.3 \\
\hline Dry on sun/oven & 138 & 24.9 \\
\hline Others (grinding, dissolve) & 26 & 4.7 \\
\hline \multicolumn{3}{|l|}{ Place of storage } \\
\hline Dry area & 329 & 59.3 \\
\hline Moist area & 24 & 4.3 \\
\hline At sun light & 67 & 12.1 \\
\hline Near fire & 135 & 24.3 \\
\hline \multicolumn{3}{|l|}{ Availability of iodized salt } \\
\hline$\geqslant 15 \mathrm{ppm}$ & 326 & 58.7 \\
\hline$<15 \mathrm{ppm}$ & 229 & 41.3 \\
\hline
\end{tabular}

Note:-ppm=parts per million.

\subsubsection{Iodized Salt Utilization}

This study shows that $48.1 \%$ (95\%CI: $44.1 \%, 52.1 \%$ ) of mothers add salt to their cooking at the end of cooking $(35.0 \%)$ or right after cooking $(13.1 \%)$ which are adequate utilization of iodized salt [Figure 2]. 


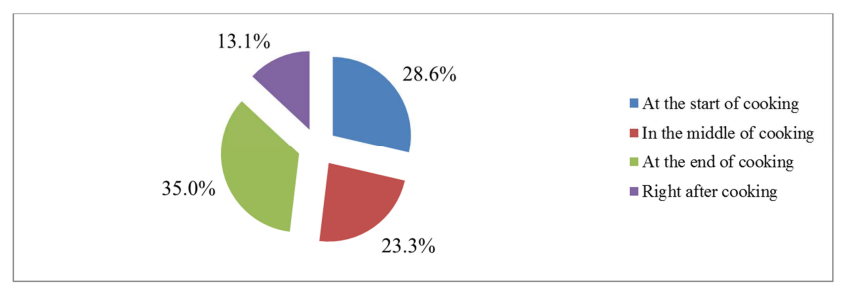

Figure 2. Time to add iodized salts to foods among pregnant mothers in Kimbibit district, Oromia, Ethiopia, $2020(n=555)$.

\subsection{Factors Associated with Adequate Utilization of Iodized Salt}

Having information about iodized salt, mother's education, residence, place of purchase, place of storage and duration of storage are candidates with adequate utilization of iodized salt in binary logistic regression. However, in the multivariable logistic regression, mother's education, residence, place of purchase, place of storage and duration of storage are significantly associated with the adequate utilization of iodized salt. Accordingly, the odds of adequate use of iodized salt are 2.46 (AOR, 2.46; 95\%CI: $1.70,3.56$ ) times higher among pregnant mothers with formal education compared to mothers with no formal education.

Moreover, the odds of adequate utilization of iodized salt among mothers who live in urban are 1.8 (AOR, 1.8; 95\%CI: $1.14,2.93)$ times higher compared rural residents. The odds of adequate utilization of iodized salt among mothers is decreased by $65 \%$ (AOR, $0.35 ; 95 \% \mathrm{CI}: 0.23,0.50)$ when purchase their salt from open market compared to those purchasing from shops. Furthermore, the odds of adequate utilization of iodized salt among mothers is decreased by $75 \%$ (AOR, 0.25; 95\%CI: $0.13,0.45$ ), 76\% (AOR, 0.24; 95\%CI: $0.13,0.45$ ) and $45 \%$ (AOR, 0.55; 95\%CI: $0.36,0.85$ ) when stored in moist, at sun light and near fire respectively compared to storing in dry area. Lastly, the odds of adequate use of iodized salt among mothers who stored their salt for more than two months is decreased by $36 \%$ (AOR, 0.64; 95\%CI: 0.42, 0.98) compared to their counter parts [Table 5].

Table 5. Factors associated with adequate utilization of iodized salt among pregnant mothers in Kimbibit district, Oromia, Ethiopia, 2020 (n=555).

\begin{tabular}{|c|c|c|c|c|}
\hline & \multicolumn{2}{|c|}{ Utilization of iodized salt by mothers } & \multirow{2}{*}{ COR [with 95\%CI] } & \multirow{2}{*}{ AOR [with 95\%CI] } \\
\hline & Adequate (\%) & Inadequate (\%) & & \\
\hline \multicolumn{5}{|l|}{ Information about iodized salt } \\
\hline No & $112(47.9)$ & $122(52.1)$ & 1 & 1 \\
\hline Yes & $176(54.8)$ & $145(45.2)$ & $1.32(0.94,1.85)$ & $0.91(0.61,1.34)$ \\
\hline \multicolumn{5}{|l|}{ Mother's education } \\
\hline No formal education & $121(41.7)$ & $169(58.3)$ & 1 & 1 \\
\hline Formal education & $167(63)$ & $98(37)$ & $2.38(1.67,3.50)^{*}$ & $2.46(1.70,3.56)^{*}$ \\
\hline Rural & $211(47.8)$ & $230(52.2)$ & 1 & 1 \\
\hline Urban & $77(67.5)$ & $37(32.5)$ & $2.27(1.47,3.5)^{*}$ & $1.8(1.14,2.93)^{*}$ \\
\hline \multicolumn{5}{|l|}{ Place of purchase } \\
\hline Shops & $141(66.5)$ & $71(33.5)$ & 1 & 1 \\
\hline Markets & $112(39.4)$ & $172(60.6)$ & $0.33(0.23,0.48)^{*}$ & $0.35(0.23,0.50)^{*}$ \\
\hline Others (bazars, wholesales) & $35(59.3)$ & $24(40.7)$ & $0.73(0.41,1.33)$ & $0.80(0.43,1.51)$ \\
\hline \multicolumn{5}{|l|}{ Place of storage } \\
\hline Moist area & $8(33.3)$ & $16(66.7)$ & $0.30(0.13,0.73)^{*}$ & $0.25(0.10,0.64)^{*}$ \\
\hline At sun light & $16(23.9)$ & $51(76.1)$ & $0.20(0.1,0.35)^{*}$ & $0.24(0.13,0.45)^{*}$ \\
\hline Near fire & $59(43.7)$ & $76(56.3)$ & $0.47(0.31,0.70)^{*}$ & $0.55(0.36,0.85)^{*}$ \\
\hline \multicolumn{5}{|l|}{ Storage time } \\
\hline$<=2$ months & $234(56.5)$ & $180(43.5)$ & 1 & 1 \\
\hline$>2$ months & $54(38.3)$ & $87(61.7)$ & $0.48(0.32,0.71)^{*}$ & $0.64(0.42,0.98)^{*}$ \\
\hline
\end{tabular}

Key notes:-* Show significantly associated factors with adequate utilization of iodized salts at $\mathrm{P}$ value $<0.25$ for simple logistic regression, and $\mathrm{P}$ value $<0.05$ for multiple logistic regression

\section{Discussion}

This study shows that $48.1 \%$ of pregnant mothers adequately use iodized salt which is far lower than the WHO's recommendation $(>90 \%)$ to eliminate IDDs [41]. This is lower than studies conducted in Sri Lanka and India which were $50 \%$ and $87.3 \%$ respectively $[14,42]$. It is also lower compared to some African countries that implemented USI and succeeded their coverage of $90 \%$ like Uganda and Kenya [43]. It is still lower than studies conducted in EDHS 2016 report of national coverage $(89 \%)$ of iodized salt [20], $68.8 \%$ in Amhara region [17], 60.8\% in Addis Ababa region [2], and $76.8 \%$ in other part of Oromia region [37].
However, the observed percentage is higher compared to findings in some European countries such as, Russia and Ukraine which was $35 \%$ and $18 \%$ respectively $[6,44]$ and the findings in some African countries that varied from 6.2$10 \%$ [45]. It is also higher compared to $37.7 \%$ in South nation and nationalities of Ethiopia [13], 33\% in Tigray region [40], and $41.9 \%$ in other parts of Oromia regions [32].

Even if there is implementation of more effective strategies to enhance universal salt iodization program by the Ethiopian Ministry of health in the last few years [20], adequately utilization is not attained in the current study. The main reasons for not to attained USI recommendations may be poor iodization technology [44], no information about the 
benefit of iodized salt (42.2\%), thought that all salts were iodized $(33.7 \%)$, purchased from open markets $(51.2 \%)$, long storage time $(25.4 \%)$, handling problems $(46.8 \%)$ and not accessible (29.7\%).

In this study, mothers' level of education was positively associated with adequate utilization of iodized salt compared to those with no education. Mothers with formal education are 2.46 times more likely to adequately use iodized salts compared with no education. This is consistent with the Study in East Shoa, Ethiopia by Mengistu Fereja that indicated adequate utilization of iodized salt among mothers with formal education [41]. The reason could be educated pregnant mothers had more information about the importance of iodized salt and IDDs which increases their decision making.

Furthermore, mothers from urban kebeles were 1.8 times more likely to adequately use iodized salt compared to those living in rural residences. This finding is supported by Zegeye Abebe in North West Ethiopia [45]. This could be related to better awareness due to access to media among urban residents which might enhance their level of understanding regarding the importance of iodized salt and information access. In addition, urban respondents have access to iodized salt everywhere and every time. Furthermore, rural residents may prefer using non-iodized salt because they perceived its low cost and they have been using it for a long time [26].

Mothers who purchase their salt from open markets are $65 \%$ lesser to adequately use iodized salt compared to those purchase from shops. A study conducted in Ethiopia [17] found that there was significant association between use of shops salt and use of iodized salts. This is so because market salt is more prone to evaporation and iodine by its nature is highly volatile as markets exposed iodized salts to sunlight [10].

Mothers, who store their iodized salt in moist area, keep at sun light and store near fire are $75 \%, 76 \%$ and $45 \%$ lesser to adequately use iodized salt respectively compared to those stored in dry areas. This is in agreement with findings in Ethiopia by multiple studies indicated a loss of iodine by $31 \%$ from iodized salt when exposed to fire and sun light because of its volatile characteristic $[18,36]$. A study by Keno T. also indicated that high humidity coupled with open cover loss 30 $98 \%$ iodine from iodized salt [15].

Duration of storage at household level was significantly associated with adequate utilization of iodized salt. Mothers who stored for greater than two months were $36 \%$ less likely to use iodized salts compared with mothers stored their salts for less than two months. This is consistent with study done by Gidey B. in Tigray region [40]. This is due to the fact that iodine is easily volatile when exposed to different environmental conditions like heat, humidity, moisture and light during storage and distribution [10, 15, 18, 36].

Therefore, education program regarding storage place, duration of salt storage at home, place of purchase on iodized salt needs to be implemented targeting the less educated mothers and rural residences.

Limitation of the Study

The possible limitation of this study is that it could not assess adequate utilization of iodized salt for salt restricted pregnant mothers.

\section{Conclusion and Recommendations}

\subsection{Conclusion}

From the respondents $48.1 \%$ adequately use iodized salt which is lower than the standard by UNICEF/WHO. Mother's education, residence, place of purchase, place of storage and duration of storage were the independent factors which affect utilization of iodized salt.

\subsection{Recommendations}

\subsubsection{Pregnant Mothers}

1) It is recommended to purchase iodized salt from shops

2) Better not to store iodized salts more than two months

3) Better to store their salt in dry area

\subsubsection{Government}

1) Enforce markets to have shadow not to expose iodized salt to moist and sun light

2) Create awareness about iodized salts among mothers focusing on rural residences

\subsubsection{Researchers}

It is better to conduct further research on iodine adequacy among salt restricted pregnant mothers using urinary iodine concentration analysis method.

\section{Lists of Abbreviations}

\author{
AOR: Adjusted odds ratio \\ CI: Confidence internal \\ CNS: Central nervous system \\ EDHS: Ethiopian Demographic and Health Survey \\ EPHI: Ethiopian Public Health Institute \\ ETB: Ethiopian birr \\ HEW: Health extension worker \\ HH: House Hold \\ ID: Iodine deficiency \\ IDD: Iodine deficiency disorder \\ IQ: Intelligent quotient \\ IS: Iodized salt \\ NNP: National nutrition program \\ PM: Pregnant mothers \\ PPM: Parts per million \\ RTK: Random test kit \\ TGP: Total goiter prevalence \\ UNICEF: United Nations Children's Fund \\ USI: Universal salt iodization \\ WHO: World Health Organization
}

\section{Declarations}

\section{Ethics Approval and Consent to Participate}

The proposal was ethically reviewed and approved by 
the institutional review board of Adama hospital medical College. The letter of support was obtained from College of Public Health and permission was obtained from Kimbibit district administration and Health Office. Kebele administrators and interviewers were informed about the purpose of study, importance and duration of the study in order to get their free time and prior informed consent for the survey. Confidentiality was maintained and respondents were informed that participation was voluntary and they can withdraw at any time from the study. The right of participants to anonymity and confidentiality were ensured by making the questionnaire anonymous. Verbal informed consent was obtained from all mothers who were involved in the study before the interview and the information given were kept confidential throughout the data collection.

\section{Consent for Publication}

'Not applicable'.

\section{Availability of Data and Materials}

The finding of this study is generated from the data collected and analyzed based on stated methods and materials. The original data supporting this finding are available from the corresponding author on reasonable request.

\section{Competing Interests}

The authors declare that they have no competing interests.

\section{Authors' Contributions}

TA participated in the design of the study, performed the data collection and the statistical analysis and served as the corresponding author of the manuscript. RW and $\mathrm{ZK}$ supervised the study, ensured quality of the data, assisted in the analysis and interpretation of the data. All authors read and approved the manuscript.

\section{Authors' Information}

1) TA is Head of Barak Woreda Health Office, Oromia Regional State, Central Ethiopia

2) RW is Maternal and Child Health (MCH) Program Coordinator, SendafaBeke Town, Ethiopia.

3) $\mathrm{ZK}$ is Water, Sanitation, Hygiene (WASH) and Neglected Tropical Diseases (NTDs) Program Coordinator, Nekemte town, Western Ethiopia.

\section{Acknowledgements}

We are grateful to Adama Hospital Medical College and Oromia regional health bureau for their cooperation during the study. Our deepest gratitude also goes to all data collectors and the study participants who have kindly cooperated in data collection, and providing the information required during the whole process of the study.

\section{References}

[1] Hine T. Assessment of iodine knowledge belief and practice of pregnant women attending western Australia's only tertiary women and neonatal hospital. Malebourne: Curtin university school of public health; 2016.

[2] Meseret Mamo Bazezew WWYaAkB. Knowledge and practice of iodized salt utilization among reproductive women in Addis: BMC research notes; 2018.

[3] Report Enms. Ethiopian national micronutrient survey: Ethiopian public health institute; 2016.

[4] El-Mani SF. Knowledge, behavior and practice of pregnant women in Wollongong regarding of folic acid and iodine nutrition after the introduction of a mandatory fortification program: university of Wollongog thesis collection; 2013.

[5] Kulwant Lakra PR. Pregnancy Outcome of Iodine Deficiency: A Study on Tribal Women in Orissa 2013.

[6] L G Holme IA, A M Lilleegen. Knowledge about iodine in pregnant and lactating women in Oslo area, Norway 2017.

[7] David L. Simpong PA, Rashid Bashiru, Martin T. Morna, Francis A. Yeboah, Kafui Akakpo and Richard K. D. Ephraim. Assessment of iodine status among pregnant women in a rural community in Ghana: Researcher gate; 2016.

[8] Wegrecki KJ, Sadig RR, Aramideh J. Iodine deficiency in pregnant women pre-and post mandatory iodine fortification in Australia-an epidemiological review.

[9] Samuel Dessu ZD, Getu Alemu. Assessment of Knowledge on Iodized Salt Utilization and Associated Factors among Households in Arba Minch Town, Southern Ethiopia: College of Medicine \& Health Sciences, Dire Dawa University, Dire Dawa Ethiopia; 2018.

[10] Gerensa H, Yohannes A, Baymot B. Knowledge, attitude and practice towards iodized salt utilization in the Hawelti kebelle, Axum, Tigray, Ethiopia 2016.

[11] Hailu S, M W, Woldie H. Iodine deficiency and associated factors among school children -Cross sectional study in Ethiopia: archieves of public health; 2016.

[12] Maalouf J, Yuan K, Perrine CJ. Iodine salt sales in the united states 2015.

[13] Wondimagegn Paulos Kumma YH, Junayde Abdurrahman, and Yohannes Mehretie Adinew. Factors Affecting the Presence of Adequately Iodized Salt at Home in Wolaita, Southern Ethiopia: Community Based Study. Sodo: College of Health Sciences and Medicine, Wolaita Sodo University, Sodo, Ethiopia; 2018.

[14] De Zoysa zed HM, Jayathilaka kapw, Liyanage Kdce. Knowledge and practice of iodine salt consumption among pregnant women in Galle district: Galle medical journal; 2015.

[15] Keno T, Threns C, Hauvai J, Kurabachew H. Iodine status on pregnant women and school children of Aira district, ethiopia: NFS journal; 2017.

[16] Ferede A. Evaluation of quantity and access of iodized salt using titration method in Arsi zone, Oromiya, Ethiopia in 2018: A Community based cross sectional study: Department of Public Health, College of Health Sciences, Arsi University, Ethiopia. 
[17] Tefera Chane Mekonnen SE, Yitbarek Wasihun, Mastewal Arefaynie, Nigus Cherie. Availability of adequately iodized salt at household level in Dessie and Combolcha Towns, South Wollo, Ethiopia 2018.

[18] Abdurrahman KaluTololu FAG, Dereje Birhanu Abitew. Coverage of Iodized Salt and Associated Factors at Household Level in Goba Town, Bale Zone, South East Ethiopia. Goba: Department of Public Health, Goba Referral Hospital, Madawalabu University, Bale Goba, Ethiopia; 2016.

[19] Hailu AA. Remarkable progress against iodine deficiency in Ethiopia: EPHI; 2017.

[20] EDHS. Ethiopian demographic and health survey: FMOH; 2016.

[21] M KR, Ittermann T, Volzke H. Factors affecting sustainable iodine deficiency elimination in Pakistan-a goal perspective 2017.

[22] Dereje Dillu JH. Iodine deficiency disorder and its correlates among antenatal care service users from Northwest Ethiopia: Evidence from Lai-Gayint District 2013.

[23] Tirhas M, Gegratsadik, Aron M. Progress and challenge on eliminating iodine deficiency in ethiopia: a systematic review: MBC nutrition; 2016.

[24] Aweke Kebede GA, Adamu Belay and Cherinet Abuye. Iodine deficiency disorder in Burie and Womberma district, west Gojjam, Ethiopia: European journal of nutrition and food saftey; 2015.

[25] Hailay Gebrearegawi Gebremariam MEY, and Digsu Negese Koye. Availability of Adequately Iodized Salt at Household Level and Associated Factors in Gondar Town, Northwest Ethiopia: North Gondar Zonal Health Department, Gondar, Ethiopia; 2013.

[26] Tweneboa M. Determinants of the use of iodized salt among pregnant women attending antinatal care at the Kaneshie polyclinic: University of Ghana; 2015.

[27] Bougma K. Effects of iodine salt on children mental and physical development in Amhara region, Ethiopia: McGill university; 2016.

[28] Mesele M, Degu G, Gebrehiwot H. Prevalence and associated factors of goiter among rural children age 6-12 years old on north west ethiopia: Mbc public health; 2014.

[29] Wolka E SS, Biadgilign S. The effect of iodine-deficiency disorders on academic achievement of schoolchildren in Southern Ethiopia.: Public Health Nutr.; 2014.

[30] ENRHI/FMOH. The Cost of hunger in Ethiopia: Implication forfor the groth and transformation of Ethiopia: Ethiopian health and nutrition institute; 2012.

[31] Newspaper I. International council for control of iodine deficiency disorders.
[32] Zerfu D. National salt iodization coverage toward prevention of iodine deficiency disorder in Ethiopia. Addis Ababa: Ethiopian Public Health Institute; 2014.

[33] IG. N. IDDNEWSLETTER 2014.

[34] FDRE, FMOH. National guideline on maternal, infant and young children nutrition 2015 .

[35] Mustapha Immurana AU. Determinants of Iodized Salt Utilization among Households with Children Under-Five in Ghana 2018.

[36] Ambaye TG. Knowledge of iodine deficiency disorders and intake of iodized salt in residence of mekelle, Tigray, Ethiopia 2015.

[37] Hawas SB LS, Mengesha ST, Demissie HF and Segni MT. Proper utilization of adequately iodized salt at household level and associated factors in Asella town Arsi Zone, ethiopia: Community based cross sectional study: Journal of food processing and technology; 2016.

[38] Eden Leka Lench DG, Menen Zegeye Kidist Fikre, Fikadu Reta, Tafese Bosha. Assessment of Handling Practices, Utilization and Concentration of Iodine in Iodized Salt at Wondo Genet town, Southern Ethiopia: A Crossectional Study 2017.

[39] Kweku M, Takhramah W, Parbey PA. Availability of adequately iodized salt at household level and associated factor to iodized salt use among household in rural community in Hohoe Ghana: World journal of pharmaceutical and medical research; 2017.

[40] B Gidey Ka, A Atinafu. Availability of adequate iodized salt at household level and associated factors in rural community in Laelay Maychew district, North Ethiopia: A cross sectional study: Journal of Nutrition and Health Sciences; 2015.

[41] Mengistu Fereja SG, Tafere Gebreegziabher, Meron Girma. Prevalence of iodine deficiency and associated factors among pregnant women in Ada district, Oromia region, Ethiopia: a cross- sectional study: School of Nutrition, Food Science and Technology, Hawassa University; 2018.

[42] Anjan Datta NK, KaushikNag, Simul Singha. A Study on Knowledge, Attitude and Practices Regarding Household Consumption of Iodized Salt among Selected Urban Women of Tripura, India 2018.

[43] Jacky M Knowles GSG, Jonathan Gorstein, Roland Kupka, Ruth Situma, Kapil Yadav,. Household Coverage with Adequately Iodized Salt Varies Greatly between Countries and by 2018 .

[44] Mannar MGV. Making salt iodization truly universal by 2020: IDD NEWSLETTER 2014.

[45] Zegeye Abebe ATaEG. Availability of adequately iodized salt in North west Ethiopia: cross sectional study: Archeive of public health; 2017. 